\title{
The Growth of Palliative Care in U.S. Hospitals: A Status Report
}

\author{
Tamara Dumanovsky, $\mathrm{PhD},{ }^{1}$ Rachel Augustin, $\mathrm{MPH},{ }^{1}$ Maggie Rogers, $\mathrm{MPH}$, \\ Katrina Lettang, BA, Diane E. Meier, MD, ${ }^{1,2}$ and R. Sean Morrison, MD ${ }^{2-4}$
}

\begin{abstract}
Background: Palliative care is expanding rapidly in the United States.

Objective: To examine variation in access to hospital palliative care.

Methods: Data were obtained from the American Hospital Association (AHA) Annual Surveys ${ }^{\mathrm{TM}}$ for Fiscal Years 2012 and 2013, the National Palliative Care Registry ${ }^{\mathrm{TM}}$, the Dartmouth Atlas of Healthcare, the American Census Bureau's American Community Survey (ACS), web searches, and telephone interviews of hospital administrators and program directors. Multivariable logistic regression was used to examine predictors of hospital palliative care programs.

Results: Sixty-seven percent of hospitals with 50 or more total facility beds reported a palliative care program. Institutional characteristics were strongly associated with the presence of a hospital palliative care program. Ninety percent of hospitals with 300 beds or more were found to have palliative care programs as compared to $56 \%$ of hospitals with fewer than 300 beds. Tax status was also a significant predictor. Not-for-profit hospitals and public hospitals were, respectively, 4.8 times and 7.1 times more likely to have a palliative care program as compared to for-profit hospitals. Palliative care penetration was highest in the New England (88\% of hospitals), Pacific (77\% of hospitals), and mid-Atlantic (77\% of hospitals) states and lowest in the west south central (43\% of hospitals) and east south central (42\% of hospitals) states.

Conclusions: This study demonstrates continued steady growth in the number of hospital palliative care programs in the United States, with almost universal access to services in large U.S. hospitals and academic medical centers. Nevertheless access to palliative care remains uneven and depends on accidents of geography and hospital ownership.
\end{abstract}

\section{Introduction}

$\mathbf{H}$ OSPITAL PALLIATIVE CARE PROGRAMS have been shown to enhance health care value for seriously ill persons both in the inpatient and the community (home, nursing home, office) setting. ${ }^{1}$ Whereas the growth of risk-sharing delivery models are shifting care of the seriously ill to community settings, hospitals are, and will remain for the near future, a major and costly site of care. We have previously reported on the growth and development of hospital palliative care programs. $^{2-5}$ Building on our four previous state-by-state comparative reports (published in 2001, 2005, 2008, and 2011), the current report uses newly available data to track the growth of hospital palliative care programs across the 50 states over the past four years and identifies areas where persistent gaps in access remain. Additionally, as in our prior reports, the study examined hospital and geographic factors associated with the development of palliative care programs and for the first time links data to regional health care utilization and spending.

\section{Methods}

The methods were similar to those used in our prior reports, ${ }^{2-5}$ with several additional modifications to enhance reporting accuracy as noted below. This study was exempt

${ }^{1}$ Center to Advance Palliative Care, ${ }^{2}$ Hertzberg Palliative Care Institute of the Brookdale Department of Geriatrics and Palliative Medicine, ${ }^{3}$ National Palliative Care Research Center, Icahn School of Medicine at Mount Sinai, New York.

${ }^{4}$ James J. Peters VA Medical Center, Bronx, New York.

Accepted September 10, 2015.

(C) Tamara Dumanovsky, Rachel Augustin, Maggie Rogers, Katrina Lettang, Diane E. Meier, R. Sean Morrison 2015; Published by Mary Ann Liebert, Inc. This Open Access article is distributed under the terms of the Creative Commons Attribution Noncommercial License (http://creativecommons.org/licenses/by-nc/4.0/) which permits any noncommercial use, distribution, and reproduction in any medium, provided the original author(s) and the source are credited. 
from institutional review board approval by the Icahn School of Medicine at Mount Sinai.

\section{Data sources}

Data were obtained from the National Palliative Care Registry ${ }^{\mathrm{TM}}$ for fiscal year 2013 (registry.capc.org), American Hospital Association (AHA) Annual Survey ${ }^{\mathrm{TM}}$ for fiscal years 2012 and 2013, 6,7 the American Census Bureau's 2013 American Community Survey (ACS), ${ }^{8}$ and from the Dartmouth Atlas of Healthcare (calendar year 2012). ${ }^{9}$ Supplemental data were provided through web searches and from telephone interviews of hospital administrators and program directors as detailed below.

Initial data on the presence of hospital palliative care programs were obtained from the National Palliative Care Registry. The National Palliative Care Registry is a repository created by the Center to Advance Palliative Care (CAPC) and the National Palliative Care Research Center (NPCRC) to collect information about the operational features of hospital palliative care programs (registry.capc.org/). Hospitals voluntarily enter operational data on an annual basis. These data have been collected annually since 2008 and include 981 participating hospitals. The data are linked to the AHA annual survey through the AHA hospital ID number.

Data on hospital characteristics were obtained from the AHA annual survey for fiscal years 2012 and 2013. ${ }^{6,7}$ The AHA surveys all member and nonmember hospitals in the United States and its associated areas on an annual basis and is considered the most comprehensive and authoritative source on U.S. hospitals and their characteristics. Among the almost 900 elements included in the survey, data are provided on the type of authority responsible for establishing policy concerning overall operation of the hospitals (federal government, nonfederal government, nongovernment not-forprofit, and for-profit); clinical facilities and services offered by the hospitals (e.g., general medical-surgical care, pediatric care, various types of intensive care units, physical rehabilitation, psychiatric services, cardiac programs, AIDS care, etc.); beds and utilization; revenues and expenses; and professional staffing levels. For facilities and services the survey also requests information on the manner in which a service is provided (i.e., whether it is hospital owned, provided by the hospital's health system, and/or provided through a formal contract between the hospital and another provider). The survey also queries hospitals as to the presence of a palliative care program. Response rates to the AHA Annual Survey average $80 \% .^{7}$

County-level characteristics were obtained from five-year estimates of the 2013 ACS from the U.S. Census Bureau; ${ }^{8}$ the ACS collects nationwide information such as age, race, income, education, and other important data. Census data were merged with primary survey data via census bureau county code. Data used in this study included level of education, ethnic makeup, age distribution, and percentage of the county population falling below the poverty line.

Physician supply, hospital mortality rates, and Medicare and hospice spending rates for Hospital Service Area (HSA) levels were obtained from the Dartmouth Atlas of Healthcare. ${ }^{9}$ HSAs are local health care markets for hospital care and are delineated ZIP codes whose residents receive most of their hospitalizations from the hospitals in that area.

\section{Hospital inclusion and exclusion}

Hospitals were included in this study if they admitted adult patients and the majority of admissions were identified as general medical-surgical, OB/GYN, cancer, or cardiac. We excluded rehabilitation hospitals; psychiatric hospitals; subacute and chronic care facilities; and eye, ear, nose, and throat hospitals. General medical surgical and chronic disease hospitals that restricted admissions primarily to children were also excluded. Hospitals containing fewer than 50 beds were excluded. A 50 bed cut-off was chosen, as hospitals smaller than this are unlikely to be able support a full interdisciplinary (nurse, social worker, physician) palliative care consultation team. All hospitals falling under federal control, (e.g., U.S. Department of Veterans Affairs) were excluded. VA hospitals are under federal mandate to reach $100 \%$ penetrance of palliative care programs. ${ }^{10}$ Hospitals that were located outside of the 50 states and the District of Columbia and hospitals that did not respond to the AHA survey were also excluded.

\section{Identification of hospital palliative care programs}

Concerns raised by correspondents to two of the authors (DEM, RSM) as to the accuracy of the AHA's reporting on the presence of palliative care programs in prior reports led to the development of a new methodology for this study. To ensure the most accurate and complete representation of hospital palliative care in the United States we completed a new multistep process. We began by identifying all hospitals that participated in the National Palliative Care Registry. We queried the registry for fiscal years 2012 and 2013 for all registrants reporting a palliative care program and crossmatched these hospitals to the AHA survey. Hospitals that were not contained within the National Palliative Care Registry underwent a web search to identify the presence of a palliative care program. A hospital was considered to have a palliative care program if the hospital website listed palliative care under "Services," displayed a palliative care program page, or referred to palliative care programs/teams on a health system or hospital webpage.

Finally, remaining hospitals without evidence of a palliative care program either from the National Palliative Care Registry or through our web search were contacted by telephone by a trained interviewer. The interviewer contacted the main hospital number and asked to be connected to the palliative care department or division. If the interviewer could not make contact with a palliative care program, they also contacted the following departments (if present) to query as to the presence of a palliative care program: nursing administration, case management, geriatrics, oncology, pain management, spiritual services, hospice, or the office of the chief nursing officer. Contact with a palliative care team member or confirmation from the aforementioned departments resulted in a "Yes" for a palliative care program for that hospital. No contact or denial of a palliative care program resulted in a "No." Telephone and web searches were conducted from June 2014 through February 2015.

\section{Analyses}

As in our two most recent reports, ${ }^{4,5}$ states were assigned a letter grade based on the percentage of hospitals within the 
state reporting palliative care programs. A grades were assigned to states in which over $80 \%$ of hospitals had palliative care programs, B grades to states with $61 \%-80 \%$ of hospitals with palliative care programs, $\mathrm{C}$ grades to states with $41 \%$ $60 \%$ of hospitals having palliative care programs, $\mathrm{D}$ grades to states with $21 \%-40 \%$ of hospitals having palliative care programs, and $\mathrm{F}$ grades to states with $20 \%$ or fewer hospitals having palliative care programs. Multivariable logistic regression models were used to examine the associations between hospital and regional characteristics and the presence of a palliative care program as described in our prior studies. ${ }^{3-5}$ Census data were linked to AHA data at the hospital county level and Dartmouth Atlas data were matched at the HSA level. Additional analyses focused on large hospitals (300 or more total facility beds) and Sole Community Provider hospitals. Although representing only $26 \%$ of all hospitals in the country, institutions with 300 beds or more account for $56 \%$ of all hospital admissions. Sole Community Provider hospital - a Medicare designation - is defined as a hospital located more than 35 miles from other like hospitals or otherwise serving as the sole provider of health care services for a region secondary to limitations in local topography or prolonged severe weather conditions. ${ }^{9}$ Analyses were performed using Stata statistical software version 13.1 (StataCorp, College Station, TX).

\section{Results}

Sixty-seven percent of hospitals (1591 of 2293) that met our inclusion criteria and had analyzable data were found to have palliative care programs (see Fig. 1 and Table 1). Seventeen states received A grades (over $80 \%$ of hospitals with palliative care programs) and seven states received a grade of D (21\%-40\% of hospitals with palliative care programs) (Fig. 2). Nine hundred and eighty-one (62\%) palliative care programs were identified through the National Palliative Care Registry, and the remaining 610 $(38 \%)$ were identified through web searches or telephone surveys. As compared to our results, the false positive and negative rates of the AHA survey's reporting of the presence of a palliative care program within its surveyed hospitals were $9.0 \%$ and $6.2 \%$ respectively.

\section{Hospital size}

Ninety percent of hospitals with 300 beds or more were found to have a palliative care program as compared to $56 \%$ of hospitals with fewer than 300 beds $(\mathrm{OR}=7.00,95 \% \mathrm{CI}$ $5.40,9.06)$. Data on hospitals with 300 or more beds are in Table 2. Hospitals of this size were 7.0 times more likely to have a palliative care program as compared to smaller hospitals $(95 \%$ CI 5.40, 9.06, $P<.001)$. Predictors of the presence of a palliative care program in hospitals with more than 300 beds included region of the country, tax status, county education level, and being an American College of Surgery approved cancer hospital or academic medical center. As in the main analyses, Sole Community Provider hospitals with more than 300 beds were significantly less likely to have a palliative care program than non-Sole Community Provider hospitals.

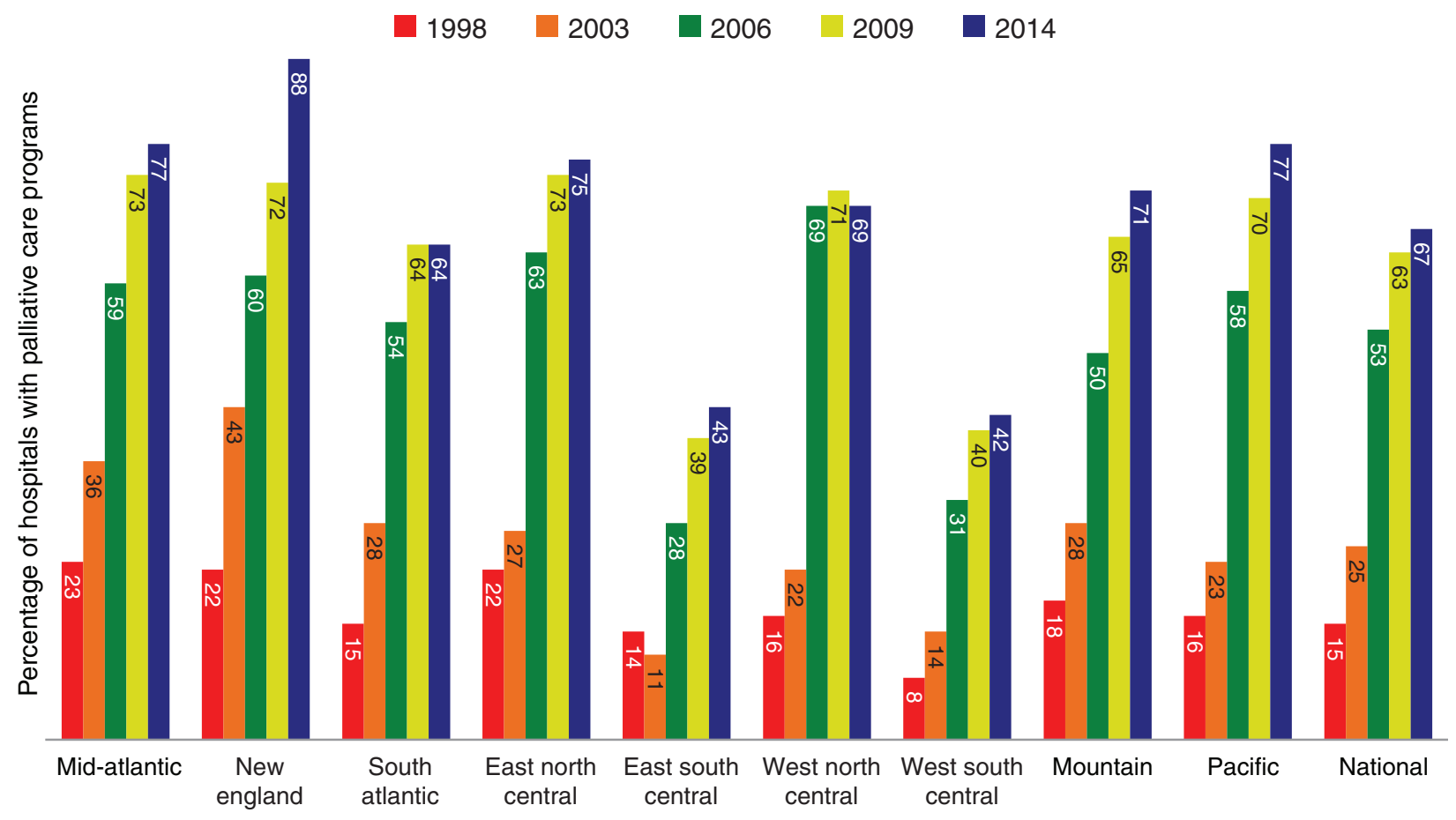

FIG. 1. Regional and national growth of palliative care programs in U.S. hospitals with 50 or more beds. The dates in the figure correspond to the fiscal year from which the data were obtained. Data from fiscal year 1998 represent unpublished data from the 2001 report. ${ }^{2}$ Data from fiscal year 2003 were published in the 2005 report, ${ }^{3}$ data from fiscal year 2006 were published in the 2008 report, ${ }^{4}$ and data from fiscal year 2009 were published in the 2011 report. ${ }^{5}$ Due to changes in our methodology, the 2015 report reflects 2014 calendar year data. Color image is available online at www.liebertpub.com/jpm 
Table 1. National and State Prevalence of Palliative Care Programs in Hospitals with 50 or More Beds (Except as Noted)

\begin{tabular}{|c|c|c|c|c|c|c|}
\hline \multirow[b]{2}{*}{$\begin{array}{l}\text { Region } \\
\text { and state }\end{array}$} & \multirow[b]{2}{*}{$\begin{array}{c}\text { All hospitals } \\
\% \text { (number) }\end{array}$} & \multirow[b]{2}{*}{$\begin{array}{c}\text { Hospitals } \\
\text { with } 300 \\
\text { or more beds } \\
\% \text { (number) }\end{array}$} & \multirow{2}{*}{$\begin{array}{c}\text { Sole } \\
\text { community } \\
\text { provider } \\
\text { hospitals } \\
\% \text { (number) }\end{array}$} & \multicolumn{3}{|c|}{ Ownership } \\
\hline & & & & $\begin{array}{l}\text { Nonprofit } \\
\text { hospitals \% } \\
\text { (number) }\end{array}$ & $\begin{array}{l}\text { For-Profit } \\
\text { hospitals \% } \\
\text { (number) }\end{array}$ & $\begin{array}{c}\text { Public } \\
\text { hospitals \% } \\
\text { (number) }\end{array}$ \\
\hline \multicolumn{7}{|l|}{ Mid Atlantic } \\
\hline New Jersey & $91.2 \%(52 / 57)$ & $100 \%(26 / 26)$ & $-(0 / 0)$ & $93 \%(49 / 53)$ & $67 \%(2 / 3)$ & $100 \%(1 / 1)$ \\
\hline New York & $78.1 \%(107 / 137)$ & $98 \%(63 / 64)$ & $43 \%(6 / 14)$ & $76 \%(88 / 116)$ & $-(0 / 0)$ & $90 \%(19 / 21)$ \\
\hline Pennsylvania & $68.3 \%(82 / 120)$ & $92 \%(36 / 39)$ & $44 \%(4 / 9)$ & $75 \%(79 / 106)$ & $21 \%(3 / 14)$ & $-(0 / 0)$ \\
\hline \multicolumn{7}{|l|}{ New England } \\
\hline Connecticut & $84.0 \%(21 / 25)$ & $100 \%(8 / 8)$ & $100 \%(1 / 1)$ & $83 \%(19 / 23)$ & $100 \%(1 / 1)$ & $100 \%(1 / 1)$ \\
\hline Maine & $78.6 \%(11 / 14)$ & $100 \%(2 / 2)$ & $50 \%(1 / 2)$ & $79 \%(11 / 14)$ & $-(0 / 0)$ & $-(0 / 0)$ \\
\hline Massachusetts & $87.8 \%(36 / 41)$ & $92 \%(12 / 13)$ & $100 \%(1 / 1)$ & $89 \%(31 / 35)$ & $100 \%(4 / 4)$ & $50 \%(1 / 2)$ \\
\hline $\begin{array}{l}\text { New } \\
\text { Hampshire }\end{array}$ & $100.0 \%(11 / 11)$ & $100 \%(1 / 1)$ & $100 \%(2 / 2)$ & $100 \%(11 / 11)$ & $-(0 / 0)$ & $-(0 / 0)$ \\
\hline Rhode Island & $88.9 \%(8 / 9)$ & $100 \%(2 / 2)$ & $-(0 / 0)$ & $89 \%(8 / 9)$ & $-(0 / 0)$ & $-(0 / 0)$ \\
\hline Vermont & $100.0 \%(4 / 4)$ & $100 \%(1 / 1)$ & $100 \%(3 / 3)$ & $100 \%(4 / 4)$ & $-(0 / 0)$ & $-(0 / 0)$ \\
\hline \multicolumn{7}{|l|}{ South Atlantic } \\
\hline Delaware & $75.0 \%(3 / 4)$ & $50 \%(1 / 2)$ & $-(0 / 0)$ & $75 \%(3 / 4)$ & $-(0 / 0)$ & $-(0 / 0)$ \\
\hline $\begin{array}{l}\text { District of } \\
\text { Columbia }\end{array}$ & $71.4 \%(5 / 7)$ & $80 \%(4 / 5)$ & $-(0 / 0)$ & $80 \%(4 / 5)$ & $100 \%(1 / 1)$ & $0 \%(0 / 1)$ \\
\hline Florida & $58.1 \%(68 / 117)$ & $84 \%(38 / 45)$ & $50 \%(1 / 2)$ & $71 \%(43 / 61)$ & $19 \%(7 / 36)$ & $90 \%(18 / 20)$ \\
\hline Georgia & $55.2 \%(32 / 58)$ & $87 \%(20 / 23)$ & $14 \%(1 / 7)$ & $66 \%(27 / 41)$ & $11 \%(1 / 9)$ & $50 \%(4 / 8)$ \\
\hline Maryland & $87.5 \%(35 / 40)$ & $100 \%(14 / 14)$ & $-(0 / 0)$ & $88 \%(35 / 40)$ & $-(0 / 0)$ & - $(0 / 0)$ \\
\hline North Carolina & $65.3 \%(47 / 72)$ & $91 \%(20 / 22)$ & $44 \%(4 / 9)$ & $71 \%(31 / 44)$ & $33 \%(2 / 6)$ & $64 \%(14 / 22)$ \\
\hline South Carolina & $58.1 \%(25 / 43)$ & $93 \%(14 / 15)$ & $33 \%(3 / 9)$ & $86 \%(18 / 21)$ & $14 \%(2 / 14)$ & $63 \%(5 / 8)$ \\
\hline Virginia & $76.9 \%(40 / 52)$ & $94 \%(15 / 16)$ & $71 \%(5 / 7)$ & $85 \%(35 / 41)$ & $25 \%(2 / 8)$ & $100 \%(3 / 3)$ \\
\hline West Virginia & $55.6 \%(15 / 27)$ & $100 \%(4 / 4)$ & $50 \%(2 / 4)$ & $67 \%(14 / 21)$ & $25 \%(1 / 4)$ & $0 \%(0 / 2)$ \\
\hline \multicolumn{7}{|c|}{ East North Central } \\
\hline Illinois & $72.1 \%(75 / 104)$ & $100 \%(30 / 30)$ & $40 \%(2 / 5)$ & $75 \%(71 / 95)$ & $40 \%(2 / 5)$ & $50 \%(2 / 4)$ \\
\hline Indiana & $67.7 \%(44 / 65)$ & $87 \%(13 / 15)$ & $50 \%(2 / 4)$ & $79 \%(34 / 43)$ & $38 \%(3 / 8)$ & $50 \%(7 / 14)$ \\
\hline Michigan & $66.7 \%(48 / 72)$ & $93 \%(26 / 28)$ & $40 \%(4 / 10)$ & $67 \%(41 / 61)$ & $100 \%(5 / 5)$ & $33 \%(2 / 6)$ \\
\hline Ohio & $82.8 \%(82 / 99)$ & $96 \%(27 / 28)$ & $67 \%(4 / 6)$ & $84 \%(76 / 90)$ & $100 \%(2 / 2)$ & $57 \%(4 / 7)$ \\
\hline Wisconsin & $87.7 \%(50 / 57)$ & $88 \%(7 / 8)$ & $100 \%(4 / 4)$ & $88 \%(49 / 56)$ & $100 \%(1 / 1)$ & $-(0 / 0)$ \\
\hline \multicolumn{7}{|c|}{ East South Central } \\
\hline Alabama & $32.0 \%(16 / 50)$ & $58 \%(7 / 12)$ & $25 \%(1 / 4)$ & $50 \%(7 / 14)$ & $6 \%(1 / 16)$ & $40 \%(8 / 20)$ \\
\hline Kentucky & $53.1 \%(26 / 49)$ & $92 \%(12 / 13)$ & $50 \%(3 / 6)$ & $63 \%(24 / 38)$ & $0 \%(0 / 7)$ & $50 \%(2 / 4)$ \\
\hline Mississippi & $28.9 \%(13 / 45)$ & $75 \%(6 / 8)$ & $0 \%(0 / 6)$ & $57 \%(8 / 14)$ & $7 \%(1 / 15)$ & $25 \%(4 / 16)$ \\
\hline Tennessee & $56.0 \%(28 / 50)$ & $74 \%(14 / 19)$ & $50 \%(1 / 2)$ & $79 \%(22 / 28)$ & $21 \%(3 / 14)$ & $38 \%(3 / 8)$ \\
\hline \multicolumn{7}{|c|}{ West North Central } \\
\hline Iowa & $66.7 \%(20 / 30)$ & $100 \%(8 / 8)$ & $50 \%(3 / 6)$ & $72 \%(18 / 25)$ & $0 \%(0 / 1)$ & $50 \%(2 / 4)$ \\
\hline Kansas & $48.5 \%(16 / 33)$ & $80 \%(4 / 5)$ & $50 \%(4 / 8)$ & $60 \%(12 / 20)$ & $14 \%(1 / 7)$ & $50 \%(3 / 6)$ \\
\hline Minnesota & $81.6 \%(31 / 38)$ & $100 \%(11 / 11)$ & $56 \%(5 / 9)$ & $82 \%(28 / 34)$ & - $(0 / 0)$ & $75 \%(3 / 4)$ \\
\hline Missouri & $66.7 \%(42 / 63)$ & $100 \%(18 / 18)$ & $40 \%(6 / 15)$ & $79 \%(33 / 42)$ & $27 \%(3 / 11)$ & $60 \%(6 / 10)$ \\
\hline Nebraska & $87.5 \%(14 / 16)$ & $100 \%(4 / 4)$ & $100 \%(4 / 4)$ & $87 \%(13 / 15)$ & $-(0 / 0)$ & $100 \%(1 / 1)$ \\
\hline North Dakota & $66.7 \%(4 / 6)$ & $50 \%(1 / 2)$ & $50 \%(1 / 2)$ & $67 \%(4 / 6)$ & $-(0 / 0)$ & $-(0 / 0)$ \\
\hline South Dakota & $88.9 \%(8 / 9)$ & $100 \%(3 / 3)$ & $67 \%(2 / 3)$ & $88 \%(7 / 8)$ & $100 \%(1 / 1)$ & $-(0 / 0)$ \\
\hline \multicolumn{7}{|c|}{ West South Central } \\
\hline Arkansas & $31.6 \%(12 / 38)$ & $75 \%(6 / 8)$ & $0 \%(0 / 11)$ & $46 \%(10 / 22)$ & $8 \%(1 / 13)$ & $33 \%(1 / 3)$ \\
\hline Louisiana & $55.8 \%(24 / 43)$ & $83 \%(10 / 12)$ & $50 \%(1 / 2)$ & $68 \%(13 / 19)$ & $38 \%(3 / 8)$ & $50 \%(8 / 16)$ \\
\hline Oklahoma & $34.9 \%(15 / 43)$ & $90 \%(9 / 10)$ & $21 \%(3 / 14)$ & $53 \%(9 / 17)$ & $21 \%(3 / 14)$ & $25 \%(3 / 12)$ \\
\hline Texas & $42.9 \%(85 / 198)$ & $66 \%(37 / 56)$ & $27 \%(4 / 15)$ & $64 \%(55 / 86)$ & $17 \%(15 / 89)$ & $65 \%(15 / 23)$ \\
\hline \multicolumn{7}{|l|}{ Mountain } \\
\hline Arizona & $68.4 \%(26 / 38)$ & $79 \%(11 / 14)$ & $60 \%(3 / 5)$ & $81 \%(25 / 31)$ & $0 \%(0 / 5)$ & $50 \%(1 / 2)$ \\
\hline Colorado & $75.7 \%(28 / 37)$ & $100 \%(11 / 11)$ & $43 \%(3 / 7)$ & $81 \%(21 / 26)$ & $71 \%(5 / 7)$ & $50 \%(2 / 4)$ \\
\hline Idaho & $66.7 \%(6 / 9)$ & $100 \%(3 / 3)$ & $33 \%(1 / 3)$ & $80 \%(4 / 5)$ & $50 \%(1 / 2)$ & $50 \%(1 / 2)$ \\
\hline Montana & $100.0 \%(9 / 9)$ & $100 \%(2 / 2)$ & $100 \%(5 / 5)$ & $100 \%(9 / 9)$ & $-(0 / 0)$ & $-(0 / 0)$ \\
\hline Nevada & $91.7 \%(11 / 12)$ & $100 \%(4 / 4)$ & $50 \%(1 / 2)$ & $100 \%(6 / 6)$ & $80 \%(4 / 5)$ & $100 \%(1 / 1)$ \\
\hline New Mexico & $35.7 \%(5 / 14)$ & $100 \%(2 / 2)$ & $17 \%(1 / 6)$ & $43 \%(3 / 7)$ & $20 \%(1 / 5)$ & $50 \%(1 / 2)$ \\
\hline Utah & $84.6 \%(11 / 13)$ & $100 \%(4 / 4)$ & $100 \%(1 / 1)$ & $100 \%(9 / 9)$ & $33 \%(1 / 3)$ & $100 \%(1 / 1)$ \\
\hline Wyoming & $33.3 \%(2 / 6)$ & $-(0 / 0)$ & $40 \%(2 / 5)$ & $0 \%(0 / 1)$ & $0 \%(0 / 1)$ & $50 \%(2 / 4)$ \\
\hline \multicolumn{7}{|l|}{ Pacific } \\
\hline Alaska & $25.0 \%(1 / 4)$ & $100 \%(1 / 1)$ & $0 \%(0 / 3)$ & $33 \%(1 / 3)$ & $0 \%(0 / 1)$ & - $(0 / 0)$ \\
\hline California & $74.0 \%(168 / 227)$ & $96 \%(71 / 74)$ & $33 \%(2 / 6)$ & $88 \%(135 / 154)$ & $17 \%(6 / 35)$ & $71 \%(27 / 38)$ \\
\hline Hawaii & $70.0 \%(7 / 10)$ & $100 \%(1 / 1)$ & $67 \%(2 / 3)$ & $75 \%(6 / 8)$ & $-(0 / 0)$ & $50 \%(1 / 2)$ \\
\hline Oregon & $88.9 \%(24 / 27)$ & $100 \%(7 / 7)$ & $100 \%(3 / 3)$ & $96 \%(22 / 23)$ & $0 \%(0 / 2)$ & $100 \%(2 / 2)$ \\
\hline Washington & $92.7 \%(38 / 41)$ & $100 \%(10 / 10)$ & $80 \%(4 / 5)$ & $100 \%(30 / 30)$ & $50 \%(1 / 2)$ & $78 \%(7 / 9)$ \\
\hline NATIONAL & $66.5(1591 / 2393)$ & $90 \%(661 / 733)$ & $45 \%(116 / 260)$ & $78 \%(1315 / 1694)$ & $23 \%(90 / 385)$ & $59 \%(186 / 314)$ \\
\hline
\end{tabular}




\section{Tax status}

Tax status also was significantly associated with the presence of a palliative care program. Not-for-profit hospitals (71\% of hospitals) and public hospitals (13\% of hospitals) were 4.8 times and 7.1 times respectively more likely to have a palliative care program as compared to forprofit hospitals (16\% of hospitals), controlling for other variables.

\section{Region}

As in prior reports, ${ }^{3-5}$ regional characteristics remain significantly associated with the presence of a hospital palliative care program (see Fig. 1 and Table 2). Palliative care penetration was highest in the New England (penetration in $88 \%$ of hospitals), Pacific (77\% of hospitals), and mid-Atlantic (77\% of hospitals) and lowest in the west south central (43\% of hospitals) and east south central (42\% of hospitals) states. States with the highest percentage of hospital palliative care programs (100\%) were Montana, New Hampshire, and Vermont; and states with the lowest percentage of programs (less than $33 \%$ of hospitals) were Alaska, Alabama, and Mississippi (see Table 1 and Fig. 2).

\section{Other institutional characteristics}

Institutional characteristics in addition to hospital size were strongly associated with the presence of a hospital palliative care program as detailed in Table 2. Forty-five percent of Sole Community Provider hospitals were found to have palliative care programs as compared to $69 \%$ of non-Sole Community Providers $(\mathrm{OR}=0.51,95 \% \mathrm{CI} 0.36,0.72)$. Other variables associated with the presence of a hospital palliative care program in regression analyses were hospitals with an American College of Graduate Medical Education accredited residency training program $(\mathrm{OR}=1.58,95 \% \mathrm{CI} 1.14,2.21)$; hospital members of the Association of American Medical Colleges (i.e., those associated with a medical school) $(\mathrm{OR}=2.31,95 \% \mathrm{CI} 1.10,4.83)$; hospitals operated by the Catholic Church $(\mathrm{OR}=3.65,95 \% \mathrm{CI}$ 2.44, 5.45); status as an American College of Surgery approved cancer hospital $(\mathrm{OR}=2.09 ; 95 \%$ CI 1.62, 2.71); and institutions that owned or had a financial relationship with a hospice program $(\mathrm{OR}=1.83 ; 95 \%$ CI $1.43,2.35)$.

\section{Access to palliative care in the setting of serious illness}

Finally, using Dartmouth Atlas data, we examined access to hospital palliative care for Medicare beneficiaries with serious

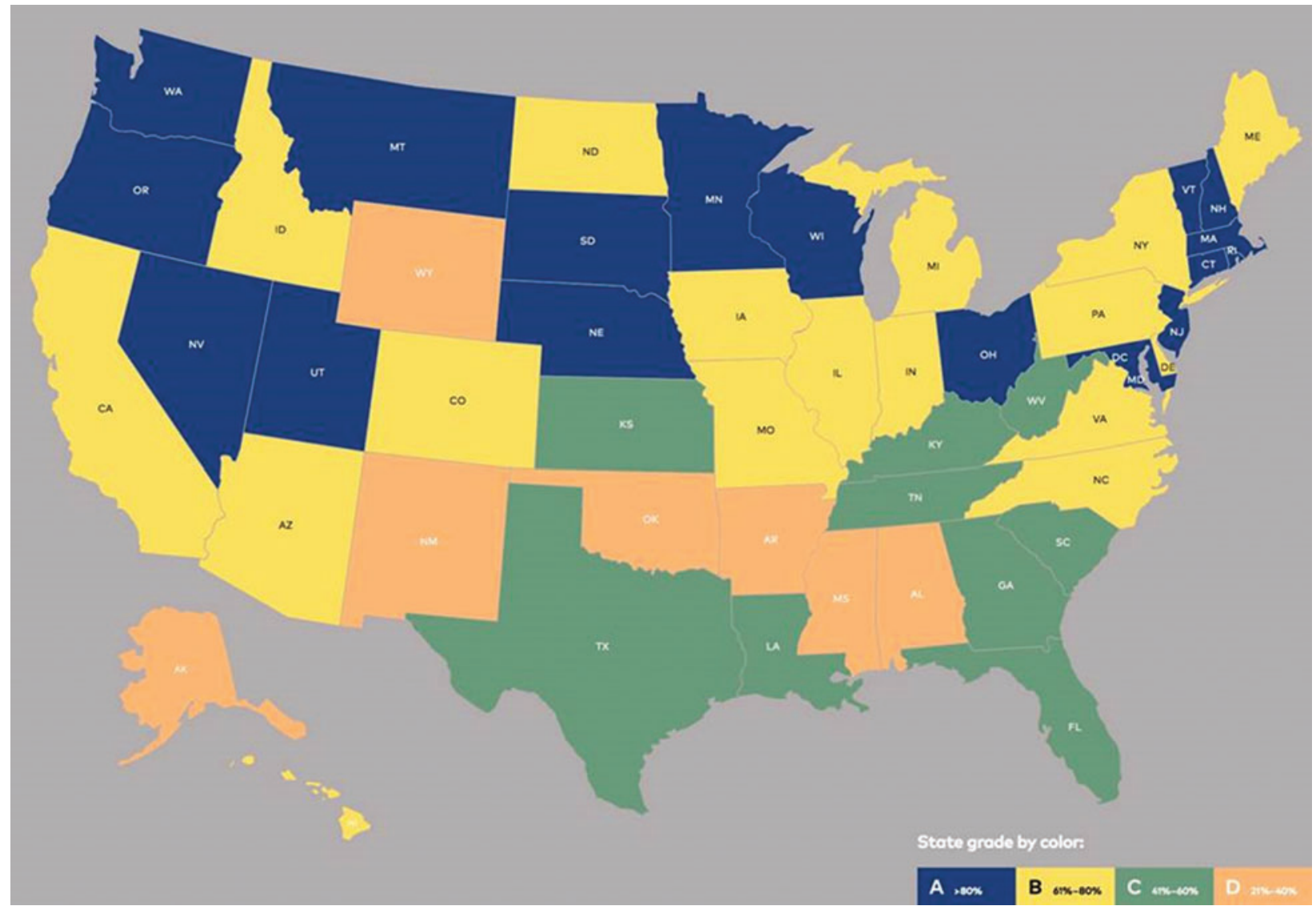

FIG. 2. Prevalence and distribution of palliative care programs in U.S hospitals with 50 or more beds. States were assigned a letter grade based on the percentage of hospitals with palliative care programs. A grades were assigned to states in which over $80 \%$ of hospitals had palliative care programs, B grades to states with $61 \%-80 \%$ of hospitals with palliative care programs, $\mathrm{C}$ grades to states with $41 \%-60 \%$ of hospitals having palliative care programs, and D grades to states with $21 \%-40 \%$ of hospitals having palliative care programs. Color image is available online at www.liebertpub.com/jpm 


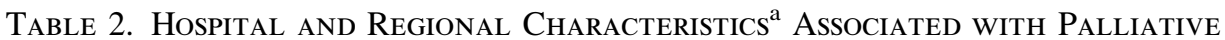
Care Programs in Hospitals with 50 or More Beds

\begin{tabular}{|c|c|c|c|c|}
\hline Characteristic & $\begin{array}{l}\text { Palliative care } \\
\text { hospitals }(\%) \\
\mathrm{N}=1591\end{array}$ & $\begin{array}{c}\text { Nonpalliative } \\
\text { care hospitals }(\%) \\
\mathrm{N}=802\end{array}$ & $\begin{array}{c}\text { Odds ratio } \\
(95 \% \text { CI })\end{array}$ & $\mathrm{P}$ \\
\hline \multicolumn{5}{|l|}{ Region } \\
\hline Mid-Atlantic (reference) & $241(77)$ & $73(23)$ & 1 & \\
\hline New England & $91(88)$ & $13(12)$ & $1.63(0.78,3.42)$ & 0.191 \\
\hline South Atlantic & $270(64)$ & $150(36)$ & $0.97(0.62,1.51)$ & 0.898 \\
\hline East north central & $299(75)$ & $98(25)$ & $1.02(0.66,1.57)$ & 0.933 \\
\hline East south central & $83(43)$ & $111(57)$ & $0.54(0.31,0.93)$ & 0.025 \\
\hline West north central & $135(69)$ & $60(31)$ & $1.05(0.61,1.79)$ & 0.859 \\
\hline West south central & $136(42)$ & $186(58)$ & $0.60(0.36,0.99)$ & 0.046 \\
\hline Mountain & $98(71)$ & $40(29)$ & $1.47(0.80,2.71)$ & 0.216 \\
\hline Pacific & $238(77)$ & $71(23)$ & $2.21(1.34,3.64)$ & 0.002 \\
\hline \multicolumn{5}{|l|}{ Hospital ownership } \\
\hline For profit (reference) & $90(23)$ & $295(77)$ & 1 & \\
\hline Public & $186(59)$ & $128(41)$ & $4.78(3.17,7.21)$ & $<0.001$ \\
\hline Not-for-profit & $1315(77)$ & $379(22)$ & $7.06(5.08,9.02)$ & $<0.001$ \\
\hline Catholic Church operated & $346(90)$ & $37(10)$ & $3.65(2.44,5.45)$ & $<0.001$ \\
\hline \multicolumn{5}{|l|}{ Hospital size } \\
\hline 50-99 beds & $201(44)$ & $258(56)$ & 1 & \\
\hline 100-199 beds & $388(54)$ & $333(46)$ & $0.945(0.70,1.28)$ & 0.720 \\
\hline 200-299 beds & $341(71)$ & $137(29)$ & $1.67(1.17,2.40)$ & 0.005 \\
\hline $300-399$ beds & $256(87)$ & $38(13)$ & $3.82(2.33,6.28)$ & $<0.001$ \\
\hline 400-499 beds & $154(91)$ & $16(9)$ & $3.99(2.04,7.79)$ & $<0.001$ \\
\hline 500 or more beds & $251(93)$ & $20(7)$ & $3.92(2.01,7.62$ & $<0.001$ \\
\hline Sole Community Provider hospitals & $116(45)$ & $144(56)$ & $0.51(0.36,0.72)$ & $<0.001$ \\
\hline $\begin{array}{l}\text { American College of Surgery } \\
\text { approved cancer program }\end{array}$ & $1002(84)$ & $187(16)$ & $2.09(1.62,2.71)$ & $<0.001$ \\
\hline ACGME approved residency program & $673(87)$ & $97(13)$ & $1.58(1.14,2.21)$ & 0.007 \\
\hline AAMC member & $245(96)$ & $10(4)$ & $2.31(1.10,4.83)$ & 0.026 \\
\hline Affiliated hospice program ${ }^{\mathrm{b}}$ & $1247(74)$ & $427(26)$ & $1.83(1.43,2.35)$ & $<0.001$ \\
\hline $\begin{array}{l}\text { Mean } \% \text { in county graduating } \\
\text { from 4-year college (SD) }\end{array}$ & $30.3(9.9)$ & $23.5(9.3)$ & $1.04(1.03,1.06)$ & $<0.001$ \\
\hline
\end{tabular}

${ }^{a}$ Other variables included in the regression equation that did not reach statistical significance $(P<0.05)$ included the presence of a hospitalist service, overall Medicare and hospice spending in the HSA, physicians per 100,000 Medicare beneficiaries in the HSA, specialist physicians per 100,000 Medicare beneficiaries in the HSA, percentage of non-Hispanic whites in the county, percentage over age 65 in the county, and percentage living in poverty in the county.

${ }^{b}$ Owned or provided by the hospital or its subsidiary, provided by the health system (in the local community), or provided through a formal contractual arrangement or joint venture with another provider that is not in the system (in the local community).

AAMC, American Association of Medical Colleges; ACGME, Accreditation Council of Graduate Medical Education; HSA, hospital service areas.

chronic illness as defined by the Dartmouth Atlas. ${ }^{9}$ The Dartmouth Atlas defines persons as seriously and chronically ill if they have one or more of nine chronic conditions associated with a high risk of death and have had at least one nonsurgical hospital admission in the last two years of life. In 2012, 652,3361 Medicare beneficiaries with serious chronic illness died in a HSA with a palliative care program (78\% of all hospital deaths of seriously ill Medicare patients).

\section{Discussion}

This state-by-state report demonstrates that access to palliative care has improved considerably over the past 16 years (see Fig. 1). At the end of 2014, two-thirds (67\%) of U.S. hospitals with 50 beds or more were found to have palliative care programs, up from 53\% in our 2008 report $^{4}$ (fiscal year 2006 data), and $15 \%$ in our first 2001 report $^{2}$ (fiscal year 1998 data). The number of states with A grades (more than $80 \%$ of the state's hospitals reporting a palli- ative care program) also increased, from $3 \%$ in the 2008 report $^{4}$ (the first year we assigned grades) to $17 \%$ in this report. For the first time, no state received a grade of $\mathrm{F}$ (20\% or fewer hospitals with palliative care programs). Over three-quarters (78\%) of Medicare hospital decedents with serious and chronic illness who died in hospital died in a HSA with a palliative care program. Important gaps still remain, however. As in prior reports, variation in access to palliative care based on region and hospital size persists. Thirty-three percent of U.S. hospitals with 50 or more beds report no palliative care services, and in onethird of the states fewer than $60 \%$ of hospitals have a palliative care program.

\section{Most large hospitals now offer palliative care services}

As of 2014, over $90 \%$ of the nation's largest hospitalsthose accounting for over half of all admissions-have 
Table 3. Hospital and Regional Characteristics ${ }^{\mathrm{a}}$ Associated with Palliative Care Programs in Hospitals with 300 or More Beds

\begin{tabular}{lcccc}
\hline Characteristic & $\begin{array}{c}\text { Palliative care } \\
\text { hospitals }(\%) \\
\mathrm{N}=661\end{array}$ & $\begin{array}{c}\text { Nonpalliative } \\
\text { care hospitals }(\%) \\
\mathrm{N}=74\end{array}$ & $\begin{array}{c}\text { Odds ratio } \\
(95 \% \text { CI) }\end{array}$ & $\mathrm{P}$ \\
\hline Region & & & & \\
$\quad$ Mid-Atlantic (reference) & $125(96)$ & $5(4)$ & $0.52(0.05,5.10)$ & 0.575 \\
New England & $26(96)$ & $1(4)$ & $0.52(0.15,1.75)$ & 0.289 \\
South Atlantic & $130(88)$ & $17(12)$ & $0.71(0.18,2.73)$ & 0.616 \\
East north central & $103(95)$ & $6(5)$ & $0.14(0.04,0.53)$ & 0.004 \\
East south central & $39(75)$ & $13(25)$ & $1.14(0.17,7.56)$ & 0.891 \\
West north central & $49(96)$ & $24(4)$ & $0.24(0.06,0.94)$ & 0.040 \\
West south central & $62(72)$ & $24(18)$ & $1.18(0.20,6.92)$ & 0.852 \\
Mountain & $37(93)$ & $3(7)$ & $2.73(0.53,14.00)$ & 0.230 \\
Pacific & $90(97)$ & $3(3)$ & & \\
Hospital ownership & & & & \\
For profit (reference) & $36(53)$ & $32(47)$ & $10.71(3.67,31.21)$ & $<0.001$ \\
Public & $100(93)$ & $8(7)$ & $6.3(3.00,13.42)$ & $<0.001$ \\
$\quad$ Not-for-Profit & $525(94)$ & $7(6)$ & $2.28(0.92,5.66)$ & 0.076 \\
Catholic Church operated & $140(95)$ & $6(21)$ & $0.22(0.07,0.68)$ & 0.009 \\
Sole Community Provider hospitals & $22(79)$ & $42(7)$ & $2.3(1.23,4.40)$ & 0.009 \\
American College of Surgery approved & $523(93)$ & $41(8)$ & $1.15(0.60,2.19)$ & 0.67 \\
$\quad$ cancer program & & $4(2)$ & $5.12(1.65,15.91)$ & 0.005 \\
ACGME approved residency program & $447(92)$ & $48(8)$ & $1.84(0.95,3.6)$ & 0.072 \\
AAMC member & $215(98)$ & $26.2(8.0)$ & $1.06(1.01,1.12)$ & 0.022 \\
Affiliated hospice program & $532(92)$ & & & \\
Mean \% in county graduating & $31.9(9.4)$ & & & \\
from 4 year college (sd) & & & & \\
\hline
\end{tabular}

${ }^{\mathrm{a}}$ Other variables included in the regression equation that did not reach statistical significance $(P<0.05)$ included the presence of a hospitalist service, overall Medicare and hospice spending in the HSA, physicians per 100,000 Medicare beneficiaries in the HSA, specialist physicians per 100,000 Medicare beneficiaries in the HSA, percentage of non-Hispanic whites in the county, percentage over age 65 in the county, and percentage living in poverty in the county.

${ }^{\mathrm{b}}$ Owned or provided by the hospital or its subsidiary, provided by the health system (in the local community), or provided through a formal contractual arrangement or joint venture with another provider that is not in the system (in the local community).

AAMC, American Association of Medical Colleges; ACGME, Accreditation Council of Graduate Medical Education; HSA, hospital service areas.

palliative care programs. Even in this category of large hospitals, however, where you live matters. For example, in the east south central and west south central regions, fewer than $75 \%$ of large hospitals report palliative care programs (see Table 3). Nationally, Sole Community Provider hospitals are less likely to provide palliative care, with $45 \%$ of these hospital types having programs.

\section{For-profit hospitals report lower rates of palliative care services}

After geography and hospital size, hospital tax status is the most significant predictor of access to hospital palliative care, and the gap between for-profits and not-for-profit hospitals has widened since our last report. For-profit hospitals of any size are less likely to provide palliative care services than nonprofit hospitals. Among hospitals with 50 beds or more, $23 \%$ of for-profit hospitals reported a palliative care program, in contrast to $78 \%$ of nonprofit hospitals and $59 \%$ of public hospitals. In hospitals with 300 beds or more, 54\% of forprofit hospitals report palliative care programs, compared to $94 \%$ of nonprofit and $93 \%$ of public hospitals. In the east south central and west south central regions, prevalence of palliative care programs in for-profit hospitals averaged $10 \%$ and $18 \%$, respectively. The reasons are unknown for differ- ences in palliative care availability in for-profit as compared to nonprofit and public hospitals.

\section{Limitations}

There are several limitations to this study that should be noted. Due to the limitations of the dataset we are only able to examine the prevalence of palliative care programs and do not, as yet, have detailed information as to their structures, staffing, hospital penetration rates (e.g., the number of patients seen), and the quality of care they provide. Although our hospital telephone and web surveys reflect 2014 prevalence rates, data for our covariates are from the most recent versions of the AHA survey, the Dartmouth Atlas, and the ACS, which date to 2012 and 2013. Finally, we should note that the registry data are self-reported by individual programs and we did not conduct additional verification of these programs. Nevertheless, as the registry requires detailed reporting of palliative care structures and processes, we are confident that submission of registry data is an accurate reflection of the presence of a hospital program.

\section{Conclusions}

This report demonstrates continued steady growth in the number of hospital palliative care programs in the United 
States, with almost universal access to such services in large U.S. hospitals and academic medical centers. Nevertheless access to palliative care remains uneven and continues to depend on accidents of geography, hospital size, and hospital ownership. One-third of U.S. hospitals report no palliative care services of any kind, and access to palliative care in community settings (home, nursing home, assisted living) is limited for people who are not hospice-eligible. Additionally, the presence of a palliative care program in a hospital does not necessarily mean that seriously ill patients needing palliative care actually receive palliative care services. As a result, most people with serious illness are unlikely to receive the care they need throughout their course of illness. Making palliative care available to the much larger population of the seriously ill who are neither hospitalized nor hospice-eligible is perhaps the single largest opportunity to improve value in in the U.S. health care system. As called for in a recent Institute of Medicine report, ${ }^{11}$ opportunities to improve access to palliative care include broad workforce training in the core principles and practices of palliative care; regulatory and accreditation requirements for high-quality palliative care services in health care settings; investment in research to strengthen the quality of care; and development of valid, actionable, and feasible measures of quality of care for this complex and vulnerable patient population.

\section{Acknowledgments}

This work was supported by grants from the National Institute on Aging (R24AG044300, P30AG028741) and the Cambia Health Foundation. Dr. Morrison is the recipient of a Clinical Research Professor Award from the American Cancer Society.

\section{Author Disclosure Statement}

The authors do not have potential conflicts of interest, including relevant financial interests, activities, relationships, and affiliations related to this manuscript. The sponsors had no role in the design, conduct, analyses, and preparation of the manuscript.

\section{References}

1. Kelley AS, Morrison RS: Palliative care for the seriously ill. N Engl J Med 2015;373:747-755.

2. Pan CX, Morrison RS, Meier DE, et al.: How prevalent are hospital-based palliative care programs? Status report and future directions. J Palliat Med 2001;4:315-324.

3. Morrison RS, Maroney-Galin C, Kralovec PD, Meier DE: The growth of palliative care programs in United States hospitals. J Palliat Med 2005;8:1127-1134.

4. Goldsmith B, Dietrich J, Du Q, Morrison RS: Variability in access to hospital palliative care in the United States. J Palliat Med 2008;11:1094-1102.

5. Morrison RS, Augustin R, Souvanna P, Meier DE: America's care of serious illness: A state-by-state report card on access to palliative care in our nation's hospitals. J Palliat Med 2011;14:1094-1096.

6. American Hospital Association: AHA Annual Survey Database $^{\mathrm{TM}}$ Fiscal Year 2012. Chicago, IL: American Hospital Association, 2013.

7. American Hospital Association: AHA Annual Survey Database $^{\mathrm{TM}}$ Fiscal Year 2013. Chicago, IL: American Hospital Association, 2014.

8. U.S. Department of Commerce: American Fact Finder. U.S. Department of Commerce, 2015. factfinder.census.gov/faces/ nav/jsf/pages/index.xhtml. (Last accessed September 6, 2015.)

9. Dartmouth Atlas of Healthcare. 2015. www.dartmouthatlas .org/. (Last accessed August 15, 2015.)

10. U.S. Department of Veterans Affairs Veterans Health Administration; Palliative Care Consult Teams. U.S. Department of Veterans Affairs, 2008.

11. Institute of Medicine: Dying in America: Improving Quality and Honoring Individual Preferences Near the End of Life. Washington, DC: Institute of Medicine, 2015.

Address correspondence to: R. Sean Morrison, MD

Hertzberg Palliative Care Institute Brookdale Department of Geriatrics and Palliative Medicine

Box 1070

Icahn School of Medicine at Mount Sinai New York, NY 10029

E-mail: sean.morrison@mssm.edu 